\title{
Crafting analytical tools to study institutional change
}

\author{
ELINOR OSTROM* \\ Workshop in Political Theory and Policy Analysis, Indiana University, USA \\ Center for the Study of Institutional Diversity, Arizona State University, USA
}

XAVIER BASURTO**

Nicholas School of the Environment, Duke University, USA

\begin{abstract}
Most powerful analytical tools used in the social sciences are well suited for studying static situations. Static and mechanistic analysis, however, is not adequate to understand the changing world in which we live. In order to adequately address the most pressing social and environmental challenges looming ahead, we need to develop analytical tools for analyzing dynamic situations particularly institutional change. In this paper, we develop an analytical tool to study institutional change, more specifically, the evolution of rules and norms. We believe that in order for such an analytical tool to be useful to develop a general theory of institutional change, it needs to enable the analyst to concisely record the processes of change in multiple specific settings so that lessons from such settings can eventually be integrated into a more general predictive theory of change.
\end{abstract}

\section{Introduction}

Darwin's 200th birthday reminds us of his major accomplishments, as well as the great challenges he faced when trying to understand the complexity of the natural world. During his voyage aboard the HMS Beagle, he dug up fossils and collected birds and plants representative of the many different ecosystems he visited. After his return, he struggled to make sense of the great diversity of life he had documented. It took him more than 20 years to explain differences between

*Email: ostrom@indiana.edu

**Email: xavier.basurto@duke.edu

An earlier version of this paper was presented at the workshop on 'Do Institutions Evolve?', Robert Schumann Center, European University Institute, Florence, Italy, 8-9 May 2009, and discussed at the Environmental Norms, Institutions, and Policies Workshop, Stanford University, 8 April 2010. We appreciate the helpful comments by Todor Arpad, Melissa Brown, James Fearon, Geoffrey Hodgson, and the other participants at these workshops. The support of the National Science Foundation and Indiana University are gratefully acknowledged. We also appreciate the editing support of Patty Lezotte and David Price. Some sections of this paper draw on, and substantially revise, sections from an earlier paper by Elinor Ostrom, 'Developing a Method for Analyzing Institutional Change', in Sandra Batie and Nicholas Mercuro (eds.), Alternative Institutional Structures: Evolution and Impact (New York: Routledge, 2008), pp. 48-76. 
related species and the mechanisms by which such life might have evolved across time and space. Darwinian theory itself has evolved considerably over time as more and more pieces of the broad puzzle were identified by researchers working in multiple disciplines at multiple levels of living entities, which enabled them to start describing the behavior of nested, complex adaptive systems (Holling, 1973; Levin, 1998).

For social science scholars to integrate complex, nested systems into their frameworks and theories, we must also recognize the extent of diversity of many forms that surrounds us and face the challenge of unpacking its complexity to explain the worlds we live in. In working toward this goal for more than a century (Veblen, 1898), the social sciences have developed powerful tools to analyze the outcomes of diverse institutional structures (King et al., 1994; Wasserman and Faust, 1994; Ragin, 2000; Bernard, 2006). Most of these tools are useful for the analysis of unchanging worlds. The fact remains, however, that the world is always changing (Nelson and Winter, 1982).

Thus, an important next step for enhancing the ability of the social sciences to unpack the complexity of the world consists of developing a cluster of tools for analyzing dynamic situations, particularly institutional change (Hodgson, 2009; Nelson, 2009; Schmid, 2004; North, 2005; E. Ostrom, 2005; Dopfer et al., 2004). The goal of this paper is to present an overview of a new diagnostic tool for analyzing institutional dynamics, mainly changes in rule systems. Given the centrality that the concept of rules has for the analysis of institutions (Hodgson, 2004), we hope the diagnostic tool will develop still further and can serve as a foundation for building a more useful theory of change, and therefore of institutional evolution. ${ }^{1}$

Our task is perhaps even more formidable than Darwin's. On the one hand, he was able to witness changes in the biological world; on the other, he struggled to explain the hidden processes behind such changes. In the social sciences, we not only struggle to explain the processes behind institutional change, but also how to identify what is changing (E. Ostrom, 2007b: 23). When we study institutional evolution, we focus on different configurations of rules that shape human interactions (North, 2005; E. Ostrom, 2005). While some analysts equate rules with what is written in legal documents, this is only one form of recording of what officials would like to think of as rules. Many rules are, however, unwritten and many written 'laws' are not followed as rules. Further, we frequently do not know which rules are accepted by individuals in their everyday interactions. Thus, the rules affecting much of our behavior are relatively invisible, which challenges our ability to identify and measure them. As we elaborate in later sections in this paper, we follow Commons's (1924) and V. Ostrom's (1980) definition of

1 By 'evolution', we follow Lustick's (2009) definition: 'that patterns of change observed among units produce subsequent patterns of population change in relation to circumstances'. Although, by populations in this paper we refer to the institutions that individuals are using rather than to the individuals themselves. 
rules as shared understandings by actors about enforced prescriptions concerning what actions (or outcomes) are required, probibited, or permitted.

We start this paper by illustrating the importance of understanding how different rule systems affect outcomes in empirical settings. To do this, we draw on our previous long-term studies of irrigation institutions in Nepal a developing country with a very heterogeneous biophysical setting. Next, we provide our working definition of rules and present the rule classification system that colleagues have designed to bring order to the wide diversity of rule systems observed in empirical settings. Then, we describe some of the multiple mechanisms of change in the context of rule systems. These sections constitute the foundation that enables us to sketch the measuring tool that we propose for studying institutional evolution in the following section of the paper. We use information about rule systems observed in our studies of irrigation systems in Nepal to illustrate the tool, and later briefly discuss how it fits with the work of other scholars also struggling to understand change and rule change in particular. To conclude the paper, we expand our scope of inquiry to discuss some of the barriers for successful rule change in developing countries. This discussion links evolutionary and institutional economics with the economics of development.

\section{Why rules are important: findings from irrigation research}

Some of the lessons coming out of our institutional analyses in Nepal and elsewhere show that resource users who have relative autonomy to design their own rules for governing and managing common-pool resources frequently achieve better economic (as well as more equitable) outcomes than when experts do this for them. ${ }^{2}$ In addition to extensive fieldwork and statistical analysis, we have used game theory to illustrate how the rules developed by resource users generate positive outcomes (Weissing and Ostrom, 1991, 1993; Gardner and Ostrom, 1991; E. Ostrom, 1995; Acheson and Gardner, 2004). We have also undertaken extensive experimental studies to verify these patterns under controlled conditions (E. Ostrom et al., 1992, 1994; Janssen et al., 2008, 2010) and used agent-based models to study complex processes of rule changes (Janssen and Ostrom, 2006a, 2006b). Using multiple methods to study core theoretical puzzles helps to increase our confidence in the patterns observed (Poteete et al., 2010).

\section{The performance of farmer-managed irrigation systems in Nepal}

Farmers have survived over the centuries in much of Asia due to their evolved knowledge of how to engineer complex irrigation systems, including dams, tunnels, and water diversion structures of varying size and complexity (Shivakoti

2 E. Ostrom (1990), Agrawal and Gupta (2005), Gibson et al. (2000), Blomquist (1992), Tang (1992), Shivakoti and Ostrom (2001), Acheson (2003), Schlager and Ostrom (1992), Basurto and Ostrom (2009). 
et al., 2005). None of these systems works well, however, without agreed-upon rules for allocating water as well as for allocating responsibilities for providing the needed labor, materials, and money to build the systems in the first place and maintain them over time. A substantial puzzle still exists, however, that relates to how resource users in the field develop rules to increase performance. As briefly summarized, we find that farmers in Nepal, who lack academic or formal training, can on average outperform highly educated engineers in the design and operation of irrigation systems. What is the process that produces these outcomes?

Colleagues associated with the Workshop in Political Theory and Policy Analysis at Indiana University (the Workshop) have jointly developed the Nepal Irrigation Institutions and Systems (NIIS) database that now has information on over 200 irrigation systems located in 29 out of the 75 districts in Nepal (Benjamin et al., 1994; Lam et al., 1994; Regmi, 2007). Our consistent finding, and that of other scholars doing research on irrigation in Nepal (Gautam et al., 1992), is that, on average, farmer-managed irrigation systems (FMIS) outperform agency-managed irrigation systems (AMIS) on multiple dimensions. In particular, a larger proportion of FMIS as contrasted to AMIS maintain the overall physical condition of the system in excellent or moderately good condition and achieve higher technical and economic efficiencies. ${ }^{3}$

The specific rules that the farmers use in governing their systems on a day-to-day basis vary substantially from one system to another. The 'official guard' on many of these systems is one of the farmers themselves who 'rotates' into this position on a regular basis. The rules specifying resource allocation, responsibilities for monitoring, and punishment vary substantially from one system to the next. Thus, the monitoring of water allocation and contributions to maintenance are largely performed by farmers who have participated in the crafting of the specific rules of their own system and have a strong interest in seeing their system perform well and ensure that others in the system are not free-riding or taking more water than their official share.

\section{How do rules originate on farmer irrigation systems?}

Farmers in old and established systems tell researchers that they do not know much about the origin of the rules they use. In Bali, for example, rules are encoded in a sacred religious system and are monitored and enforced by priests (Lansing, 1991, 2006). Agricultural scientists, engineers, and government officials treated these systems as based only on superstition. After the government of Indonesia required higher rice production by farmers in Bali, external experts tried to teach the farmers how to manage their irrigation systems in a 'modern and more efficient manner'. The rice varieties of the green revolution were recommended

3 See Lam (1998) for definitions of these concepts and Lam and Ostrom (2010) for an over-time analysis of rules and other factors as they affect performance of FMIS. 
in order to reach three crops per year (Spiertz, 1991). This change meant that the farmers did not follow their original rhythm of rice production. The experts eventually discovered, however, that the age-old system was actually relatively sophisticated in its manner of averting the spread of pests as well as careful coordination of water delivery itself. In light of disastrous pest outbreaks after some of the farmers changed their earlier practices, the experts have had to reverse their earlier efforts to make the peasants adopt modern management techniques for the irrigation systems (Lansing and Kremer, 1993; Janssen, 2007).

In discussions with farmers who have built and managed more recent systems, one hears about how hard it is to find the right combination of rules that work in a particular setting. They have had to try out multiple combinations of rules and keep making small adjustments to get the system working well and ensure that most farmers actually follow the rules that they decide upon. Even when those closely involved in governing and managing a resource do have relative autonomy to devise their own rules, they cannot foresee all the outcomes that a change in rules produces (Hilton, 1990; Shivakoti et al., 1997; Shivakoti, 1992). They have to learn over time by tinkering with rules so as to cope with diverse biophysical systems, including rainfall patterns, soil, geology, as well as with the cultural and economic systems in which they live.

The study of irrigation systems in Nepal is only one of the empirical studies we have undertaken over the past quarter of a century focusing on institutional arrangements and their impact on incentives, behavior, and outcomes. Colleagues associated with the Workshop have also undertaken a study over time of more than 200 forests located in 12 countries, where we have identified a very large number of rules actually used in practice (E. Ostrom and Nagendra, 2006; Hayes and Ostrom, 2005; Gibson et al., 2005b; Coleman, 2009). ${ }^{4}$

\section{What do rule structures look like?}

Developing a reliable way to describe a given rule structure is the first step toward being able to compare such a structure at a hypothetical time zero, and at subsequent time periods, and thus begin to explain institutional change. We also need to make a fundamental distinction between strategies, norms, and rules (Crawford and Ostrom, 2005). Strategies are the plans made by individuals in a situation as to what actions they plan to undertake so as to achieve outcomes given their information about the basic structure of the situation. Norms and rules both contain prescriptions - the musts, must nots, and mays of deontic logic.

4 Because the diversity of potential rules is so large, we should not assume that the choice of institutional rules to improve the performance of a given action situation is a process of designing optimal rules (E. Ostrom, 2007a). 
Norms are prescriptions about actions or outcomes that are not focused primarily on short-term material payoffs to self. A participant who holds a truthtelling norm gains an internal reward (that can be modeled as an additional value added to their utility function) for telling the truth even when material payoffs would be greater when telling a lie (Crawford and Ostrom, 2005). While norms can emerge entirely internal to an individual, most norms are acquired in the context of a community in which the individual frequently interacts. Thus, the chance that others in a relevant community may learn about a norm-breaking action strongly reinforces the internal value assigned to the norm-conforming action (see Richerson and Boyd, 2005, for an important analysis of the role of shared norms in cultural evolution).

Rules are linguistic statements containing prescriptions similar to norms, but rules carry an additional, assigned sanction if forbidden actions are taken and observed by a monitor (Commons, 1924). ${ }^{5}$ For rules to exist, any particular situation must be linked to a rule-making situation and some kind of monitoring and sanctioning must exist (Crawford and Ostrom, 2005; Basurto et al., 2009). In effect, rules are the result of implicit or explicit efforts to achieve order and predictability among humans by creating classes of persons (positions) who are then required, permitted, or forbidden to take classes of actions in relation to required, permitted, or forbidden outcomes or face the likelihood of being monitored and sanctioned in a predictable fashion (V. Ostrom, 1991). Rules may be crafted in any of a wide diversity of collective-choice or constitutional-choice arenas in local, regional, national, or international domains. Contemporary scholarship tends to focus on rules that are formally prescribed by a national government, but we must understand the process of rule change at a community level as well, even when the rules-in-use are not formally written by those using them to structure their daily interactions.

Having provided a basic definition of norms and rules, we can now describe the rule classification system based on the Institutional Analysis and Development (IAD) framework developed by colleagues at the Workshop. ${ }^{6}$ We rely on this rule classification system to help explain the immense variety of small differences with which humans are confronted in everyday action situations. Our basic assumption is that underlying such differences are nested layers, each composed by different configurations of the same set of elements (i.e., different configurations of rule types). Thus, it is the configurational nature of the set of elements present in each of these layers that helps to explain the great complexity observed in the world.

5 For a more in-depth discussion on the difference between rules and norms, see E. Ostrom (2005: chaps. 5 and 6).

6 While the classification was developed for rules, there is no reason why this classification cannot be applied to the study of norms as well. 
Our broad rule classification system is based on game-theoretical tools that have provided us with a formal language to express the structure of relatively simple and unambiguous action situations, such as games. We build on gametheoretical language to create a systematic way to classify generic rules and thus join formal theorists in the assumption that any human interaction is composed of seven working parts: Actors in positions choosing among actions at particular stages of a decision process in light of their control over a choice node, the information they have, the outcomes that are likely, and the benefits and costs they perceive for these outcomes. Those familiar with game-theoretic analyses will recognize these seven elements as the moving parts of any formal game. So, in our effort to bring some order to the massive number of specific rules that one could analyze in any particular action situation, we have clustered rules into seven broad types based on the seven working parts of a game or of an action situation. $^{7}$

We start by identifying the set of positions or anonymous slots that are filled by actors and to which specific action sets are assigned at junctures in a decision process. Position rules create these positions and they may also state whether there is a defined number, no limit, a lower limit, or an upper limit on the number of actors who hold a position (E. Ostrom, 2005). Boundary rules - frequently called entry and exit rules - define (1) who is eligible to enter a position, (2) the process that determines which eligible actors may enter (or must enter) positions, and (3) how an individual may leave (or must leave) a position. Choice rules specify what a participant occupying a position must, must not, or may do at a particular point in a decision process in light of conditions that have, or have not, been met at that point in the process.

Aggregation rules determine 'who is to decide' which action or set of activities is to be undertaken. Crawford and Ostrom (2005) describe the different generic forms that aggregation rules can take depending on whether a decision of a single actor or of multiple actors needs to be weighted differently or not, and when rules define outcomes in cases of non-agreement. Information rules affect the level of information available to actors about actions and the link between actions and outcomes. Information rules authorize channels of information flow among actors, assign the obligation, permission, or prohibition to communicate to actors in positions at particular decision nodes, and the language and form in which communication will take place (Crawford and Ostrom, 2005). Information rules are particularly important in generating information about past actions of actors

7 How broad are these seven types of rules? Those in the natural sciences can think of them as broad as different phyla would be in the Linnaean classification system. It is not useful to think of the rule typology as a tool to exhaustively categorize the myriad of rules that can be present in an action situation. Rather, its aim is to provide the analyst with the basic components of a general recipe for creating action situations. 
Table 1. Default conditions

\begin{tabular}{|c|c|}
\hline Default position condition & No formal positions exist. \\
\hline Default entry condition & Anyone can enter. \\
\hline Default choice condition & Each player can take any physically possible action. \\
\hline Default aggregation condition & $\begin{array}{l}\text { Players act independently. Physical relationships present in the } \\
\text { situation determine the aggregation of individual moves into } \\
\text { outcomes. }\end{array}$ \\
\hline Default information condition & $\begin{array}{l}\text { Each player can communicate any information via any channel } \\
\text { available to the player. }\end{array}$ \\
\hline Default payoff condition & $\begin{array}{l}\text { Any player can retain any outcome that the player can physically } \\
\text { obtain and defend. }\end{array}$ \\
\hline Default scope condition & Each player can affect any state of world that is physically possible. \\
\hline
\end{tabular}

Source: Adapted from E. Ostrom (2005: 211).

so that other actors can know who is, or is not, trustworthy (see Janssen and Ostrom, 2006b).

Payoff rules affect the benefits and costs assigned to actors in light of the outcomes achieved and the actions chosen by the actors. An example of a set of payoff rules is the pay schedule that is used by a government agency or by a private firm to assign salaries to actors in particular positions. Finally, scope rules determine which outcomes may, must, or must not be affected within a situation. Scope rules are especially useful for those situations where establishing rules that monitor actions of players might be more difficult or sensitive than monitoring outcomes. For instance, rules that specify a limit on particular types of pollutants in a smokestack limit outcomes, but do not focus on the variety of actions that might produce those outcomes. ${ }^{8}$

Certainly, there are situations where rules do not exist that are related to all elements of an action situation. In Table 1, we present the default conditions for each rule type, and it is akin to what the structure of a game or action situation would look like in the absence of any rules.

\section{What are some of the processes of rule change?}

Given the logic of combinatorics, ${ }^{9}$ it is impossible for public officials, or for direct beneficiaries, to conduct a complete analysis of the expected personal benefits, or broader performance, of all of the potential rule changes that could be made by individuals operating within a hierarchy, market, or common-pool resource

8 For a more in-depth description of the rule typology, see E. Ostrom (2005: chap. 7).

9 Combinatorics and enumerative combinatorics, in particular, is a branch of mathematics concerned with the number of ways that certain patterns can be formed. Assuming that rules can be either present or absent, a system that has $n$ number of rules has $2 n$ possible configurations. Each time a rule is added to a particular rule system, the number of configurations increases exponentially. 
system. A similar impossibility also exists for biological systems - they evolve. Let us explore these similarities and their differences.

Rule or policy systems have two structures that are somewhat parallel in their function to the concepts of a genotype and a phenotype in biological systems. The genotypic structure characterizes the set of instructions encoded in DNA to produce an organism with a particular phenotypic structure. Phenotypic structures characterize an expressed organism - how bones, organs, and muscles develop, relate, and function in an organism in a particular environment. A rule configuration is parallel in function to a genotype in that rules like genotypes are mechanisms that transmit information about how to produce something (a protein of a particular organ or an action situation in a particular environment). In other words, rules are a set of instructions of how to produce the expressed situation or the structure of relationships among individuals that is also affected by the biophysical world and the kind of community or culture in which an action situation is located. The components of an action situation (or a game) characterize an expressed situation - how the number of actors, the information available, and their opportunities and costs create incentives, and how incentives lead to types of outcomes in a particular environment.

While rule (and norm) systems can evolve, their evolution and that of any cultural phenomena involves different mechanisms from those involved in the evolution of species (Boyd and Richerson, 1985; Richerson and Boyd, 2005; Campbell, 1975; Nelson and Winter, 1982; Greif and Laitin, 2004; Nelson, 2009). Furthermore, as Lustick (2009) elaborates, the evolution of a rule system is not synonymous with progress. Certainly, evolutionary processes do not entail a priori judgments on the outcome. Evolutionary processes do involve, however, the generation of new alternatives, selection among new and old combinations of structural attributes, and retention of those combinations of attributes that are successful in a particular environment. In evolving biological systems, genotypic structures are changed through blind variation or directed variation (such as in the case of the domestication of many species of plants and animals). In evolving human-based rule systems, rule configurations within an action situation can change as a result of many self-conscious or unconscious mechanisms, including trial-and-error efforts, especially in collective-action processes. In some instances, the capacity of the biophysical resource system to buffer abuse from trial-anderror of different rule systems seems to play a necessary but not sufficient role in the emergence of successful self-governed rule systems (Basurto, 2008; Basurto and Coleman, 2010). Mechanisms for change in rule configurations can be roughly divided into relatively self-conscious and unconscious processes of change. Among examples of self-conscious processes that are frequently mentioned in the literature are those driven by imitation (Richerson and Boyd, 2005). Imitation of rules used by others can lead to rule evolution over time, especially if the farmers from multiple irrigation systems in a region regularly interact in a local market or other regular meeting place. Imitation of entire 
rule systems that are thought of as 'successful' can also take place at the constitutional-choice level, such as the case of the adoption of the US National Parks' law system by the Costa Rican nascent national park system. Other selfconscious processes of change in rule systems include some cases of external development interventions, such as when external aid support is conditioned to changes in local institutions based on foreign views of fairness, productivity, democracy, or development itself.

Rapid changes in the biophysical characteristics of a resource can lead resource users to mobilize enough incentives to organize and self-consciously reform their governance rule systems to new conditions. However, when changes are slow over space or time, and confounded with seasonal and other biophysical variables, users might find themselves unconsciously adapting to shifting conditions in an effort to maintain certain levels of productivity, equitable distribution, or sustainability (Berkes and Folke, 1998; Berkes, 2007; Meinzen-Dick, 2007; Wilson et al., 2007). Competitive processes can also lead some users to self-consciously favor some institutional arrangements over others. Similarly, conflict over the interpretation of rules is also a process that frequently leads to self-conscious change. If there are regularized procedures for hearing conflict and reaching solutions that are accepted by actors as legitimate, rules may be added, taken away, or modified as a result of such procedures. In commonlaw settings, one can expect those disadvantaged by current rules to challenge them and even continue to challenge initial decisions against them until they gain an interpretation favorable to their situation (Stake, 2005). Most self-conscious processes of change are based on the ability of humans to learn (Henry, 2009), such as when members of a rural fishing community organize to modify rules to control levels of exploitation based on past experiences (Basurto, 2005).

Unconscious processes of change include forgetting, like when there is a very large number of rules and no one 'remembers' them all without extensive research, or when laws are never practiced. The same phenomena are observed when certain taboos disappear through language loss, cognitive dissonance, technological change, or non-enforcement. These mechanisms can slowly erode rule systems, which then wither away and eventually can be replaced by new practices and norms of behavior (Kofinas, 2005). ${ }^{10}$

For sociocultural anthropologists, other unconscious processes of rule changes include sociocultural epistasis. This form of change takes place when the semiotic overlap of one idea necessarily implies a subsequent idea, even though both ideas might not necessarily be related. Nevertheless, through cultural epistasis both ideas are continually associated and carried along in processes of change (Brown and Feldman, 2009).

10 'Forgetting' might also constitute a strategic move that advantages some actors with the hope that others may have forgotten this rule and not challenge them for breaking it. 
Our dependence on language to communicate and the inherent ambiguity of language can lead to a number of unconscious processes of rule change as well. Rules are composed of mere words and, as Vincent Ostrom (1997) has frequently pointed out, words are not always understood by everyone with the same meaning (see also 2008a, 2008b). A guard may not understand the rules the same way as users. A guard, for example, may interpret rules that place heavy costs on the guard in contrast to those rules that involve low costs. Babbling equilibrium problems are widespread, even among scholars studying rules and norms systems! And, it is a key problem for the social sciences (E. Ostrom, 2005: 179). ${ }^{11}$

For these and other reasons, recording the rule systems that people use to govern their interactions is a challenge. Moreover, many rules have evolved over multiple centuries, as those used in regulating the Bali irrigation systems described by Lansing (2006), the Alpine meadows described by Netting (1981), or customary law in England, Norway, and Africa (Orebech et al., 2005). In many instances, the original rules were not written down. Nor, have all changes been recorded in many of these systems. While other rule systems may be of more recent origin, users may not have been committed to recording them in written form (such as for many farmer-constructed and managed irrigation systems in developing countries) (Tang, 1992; Lam, 1998; Shivakoti and Ostrom, 2001).

\section{How can we measure changes in rule configurations?}

We will leave the above challenges aside to focus on what is being changed when resource users change rules. What do these underlying building blocks for creating an action situation look like? To simplify our effort, we start with a situation without any rules (i.e., the default condition presented in Table 1). This is akin to imagining Nepali irrigators involved in appropriating water in a 'state of nature'. The set presented in Table 1 also is useful to illustrate the initial conditions of a common-law legal system. ${ }^{12}$ If one wants to analyze rule changes, the initial situation before any rules are established is the base situation. Hobbes's analysis of the state of nature and Garrett Hardin's (1968) analysis of 'The Tragedy of the Commons' implicitly relied on the above set of default conditions as structuring the situations they analyzed.

The default conditions are then changed through any of the mechanisms briefly described in the previous section. For an irrigation system governed by the farmers it serves, for example, the rule-changing process might be an annual

11 A babbling equilibrium problem is present when communicators engaged in a signaling game do not understand each other's signals in the same way. Part of the impetus to develop the grammar of institutions and its syntax (Crawford and Ostrom, 2005) was to address this problem. Also see Basurto et al. (2009).

12 In a Roman-law country, the default conditions would be entirely different since Roman-law systems presume that most things are forbidden unless specifically permitted. 
Table 2. Norms or rules frequently identified in field studies of irrigation systems ${ }^{\mathrm{a}}$

\section{Boundary rules}

B1 Land: ownership or leasing of land within a specified location

B2 Shares: ownership or leasing of transferable shares independent of land but in proportion to water flow

B3 Membership: belong to a group in order to receive water

\section{Position rules}

P1 Rotation: water users rotate into monitor position

P2 External monitor: hire guard from outside water user community

P3 Local monitor: hire guard from inside water user community

Choice (Allocation) rules ${ }^{\mathrm{b}}$

C1 Fixed percentage: the flow of water is divided into fixed proportions according to the land owned or some other formula

C2 Fixed time slot: each individual (or subcanal) assigned fixed time during which water may be withdrawn

C3 Fixed order: farmers take turns to get water in the order in which they are located on a canal (or some other clear assignment)

\section{Information rules}

I1 Rule infraction publicity: announcement made in some public manner

I2 Measurement: size of diversion weir publicly measured

I3 Reporting: written minutes and financial reports available to all

\section{Aggregation rules}

A1 Neighbor agreement: both farmers present and agree at time-slot change

A2 Community votes: define time to change from one allocation rule to another

A3 Monitor decision: if farmers disagree, monitor has the final word

\section{Payoff rules}

Y1 Penalty: farmers contribute money, labor, or some other resource for breaking a rule

Y2 Water tax: farmers pay an annual financial tax

Y3 Labor obligation: farmers contribute labor (according to an agreed formula) for regular maintenance and emergency repair

\section{Scope rules}

S1 Geographic domain: define extent of land to which water may be applied

S2 Water use: define limits on use of water obtained from a system

S3 Crops: define limits on crops that may be grown using water from a system

Notes: ${ }^{a}$ We use the $[\mathrm{S} / \mathrm{R} / \mathrm{P} / \mathrm{F}]$ as a placeholder for any of the different operators for norms (i.e., should) and rules (i.e., required/permitted/forbidden) that could be appropriate for a given action situation.

${ }^{b}$ We refer to these rules as choice rules, as they allow an individual to choose from zero water up to some upper limit. Thus, at the individual level, the allocation rule states what is permitted. At the system level, the rule requires that the specified type of allocation be enforced.

meeting of all of the farmers or a Water User Committee elected by the farmers. For governmental systems, the rules may be prescribed by an administrative agency of the state or national government involved. ${ }^{13}$

For purposes of clarity and presentation, in Table 2 we have arrayed a set of three frequently used norms or rule statements for each of the seven types

13 In some situations, multiple collective-choice organizations compete to make the rules for an operational situation, but that problem is beyond the scope of this paper. 
of rules discussed above for an operational-level irrigation system. ${ }^{14}$ Three rule statements for each type of rule is a very small set given the large number of rules of each type we have recorded from case studies written about resource government institutions in the world. However, our aim here is not to examine the full inventory of all rules already identified but to present the underpinnings of a tool for recording and analyzing institutional change. Note that depending on what operator is used in each statement, it would be coded as a norm (if operator is 'should') or a rule (if operator is either 'required', 'permitted', or 'forbidden').

We draw on, and slightly modify, the method that Blomquist, Schlager, Tang, and Ostrom used in coding rules for the meta-analysis reported in the third section of E. Ostrom et al. (1994) and in E. Ostrom (1999). Rules that have frequently been used in governing irrigation systems are listed in Table 2 and then arrayed as columns in the rule inventory of Table 3 (see Tang, 1992, for a description of these rules). The inventory is divided into seven broad fields with specific rule statements (described in Table 2) that might be a norm or a rule or the absence of either prescription. ${ }^{15}$ If no norm or rule is used at all, the rule statement is coded 0 . If a norm has evolved that actors 'should' follow a particular prescription, an $S$ will be entered for that prescription. If a rule has been established, the statement is coded as either:

$\mathrm{R}=$ Required; $\mathrm{P}=$ Permitted; or $\mathrm{F}=$ Forbidden

This method will be used to examine processes of rule change and the fit of rules to biophysical and community characteristics of a particular setting. In Table 3, we have used the numbering system of Table 2 for the columns. Thus, the three columns under the heading Boundary Rules in Table 3 represent the three rules listed under that category in Table 2 . The other numeric column headings in Table 3 are similarly described in Table 2.

The first row of Table 3 represents a Rule Configuration at time one (T1) when there are no norms or rules in use - all entries are zeros. Thus, Row 1 represents a lawless 'state of nature' that Hardin (1968) envisioned leading to a 'tragedy' of the commons. If one were to model the resulting appropriation situation as a formal game (assuming that the farmers live next to a water source and have a high demand for the water), the Nash equilibrium would be an inefficient level of water withdrawal (E. Ostrom et al., 1994: chap. 3). Thus, the prediction for behavior and outcomes in an irrigation game constituted by the total absence of normative prescriptions is that every farmer grabs as much water as they can

14 The rule statements we chose as examples of boundary, choice, and payoff rules are the rules that Tang (1992) identified as the most frequently observed rules in his meta-analysis of irrigation cases located in many different countries. The rule statements that we chose for the other rules are derived from extensive field research regarding irrigation systems in many countries - particularly Nepal (see Shivakoti and Ostrom, 2001; Joshi et al., 2000).

15 We have long relied on the symbols used in deontic logic for modal operators. For background, see Hilpinen (1981) and von Wright (1951, 1963). 
Table 3. Rule or norm configuration inventory

\begin{tabular}{|c|c|c|c|c|c|c|c|c|c|c|c|c|c|c|c|c|c|c|c|c|c|}
\hline \multirow{2}{*}{$\begin{array}{l}\text { Potential Rules } \\
\text { or Norms }\end{array}$} & \multicolumn{3}{|c|}{ Boundary } & \multicolumn{3}{|c|}{ Position } & \multicolumn{3}{|c|}{$\begin{array}{l}\text { Choice } \\
\text { (Allocation) }\end{array}$} & \multicolumn{3}{|c|}{ Aggregation } & \multicolumn{3}{|c|}{ Information } & \multicolumn{3}{|c|}{ Payoff } & \multicolumn{3}{|c|}{ Scope } \\
\hline & B1 & B2 & B3 & P1 & P2 & P3 & $\mathrm{C} 1$ & $\mathrm{C} 2$ & $\mathrm{C} 3$ & A1 & A2 & A3 & I1 & I2 & I3 & Y1 & $\mathrm{Y} 2$ & $\mathrm{Y} 3$ & S1 & S2 & S3 \\
\hline Configuration T1 & 0 & 0 & 0 & 0 & 0 & 0 & 0 & 0 & 0 & 0 & 0 & 0 & 0 & 0 & 0 & 0 & 0 & 0 & 0 & 0 & 0 \\
\hline Configuration T2 & $\mathrm{S}$ & 0 & 0 & 0 & 0 & 0 & 0 & 0 & $\mathrm{~S}$ & 0 & 0 & 0 & 0 & 0 & 0 & 0 & 0 & $\mathrm{~S}$ & 0 & 0 & 0 \\
\hline Configuration $\mathrm{T} 3$ & S & 0 & 0 & $\mathrm{R}$ & 0 & 0 & 0 & 0 & $\mathrm{R}$ & $\mathrm{R}$ & 0 & 0 & 0 & 0 & 0 & $\mathrm{R}$ & 0 & S & 0 & 0 & 0 \\
\hline Configuration T4 & S & 0 & 0 & $\mathrm{R}$ & 0 & 0 & $\mathrm{P}$ & 0 & 0 & $\mathrm{R}$ & 0 & 0 & 0 & 0 & 0 & $\mathrm{R}$ & 0 & $\mathrm{~S}$ & 0 & 0 & 0 \\
\hline Configuration T5 & $\mathrm{R}$ & 0 & 0 & $\mathrm{R}$ & 0 & 0 & $P$ & 0 & 0 & $\mathrm{R}$ & 0 & 0 & 0 & 0 & 0 & $\mathrm{R}$ & 0 & S & 0 & 0 & $\mathrm{~F}$ \\
\hline
\end{tabular}


when it is available. This would mean that the farmers located at the head end of a system would obtain most of the water. The overall crop yield for the system as a whole would be below the yield that would be feasible if water were allocated to all of the parcels adjacent to the system.

\section{Relying on norms}

For very simple and isolated systems, the farmers located adjacent to a system might develop a simple set of norms over time that would lead to a water rotation system along the canal. If there were 14 farmers and they agreed on a simple set of norms such as: only the 14 farmers should take water from system, no watering at night, and each farmer takes a half-a-day turn before turning the water distribution over to the next farmer, it is conceivable that such a set of norms - coded as S in Row T2 - might suffice for some time. They would need three norms: (1) only the 14 adjacent farmers should use the irrigation water B1, (2) they should rotate water distribution during the daylight hours following a specific schedule - C3, and (3) everyone should maintain the canal in front of their own farm and pitch in and help in times of emergency repair - Y3.

Such a simple norm-based system might survive for a long time if the land were relatively flat so headenders did not have a strong advantage given to them by nature, if the land was always inherited by one child (rather than being divided each generation - a general inheritance rule for a larger community ${ }^{16}$ ), if no one sold their land to outsiders, and if the system was relatively isolated from changes in the value of land, labor, or commodities. These are four large 'ifs'. Robert Netting (1974) described such a system in his fieldwork in Switzerland, and to our knowledge this is the only irrigation system where the farmers rely on norms alone. Given the high value of irrigation water for many families (since their survival depends on their getting enough water), conflicts can easily arise over who takes water under what conditions. Conflicts undermine shared norms if they are not resolved.

\section{Changing rules within collective-choice arenas}

Conflict could arise and stimulate changes to the use of rules in this simple system in many ways. As an example, if one of the 14 farming households sold their land, a new resident might argue that they bought the land in order to grow a crop that requires more water than the other farmers in the system. If they began to take water at night or try to take a longer turn than the norm, conflict would certainly be generated. This would likely lead to a meeting of the farmers. The farmers might decide to organize a Water Users Association. Then, within a collective-choice situation in the new association, they could decide to make four new rules while keeping the two norms (coded as S) about a limited number

16 The rules set for any one interaction situation are always affected by rules determined by larger regimes - such as the inheritance rules in force. 
of irrigators having access to the irrigation water (B1), and contributing labor for maintaining the canal (Y3). We exemplify the four new rules (coded as R) in the configuration at $\mathrm{T} 3$ of Table 3:

1. create a new position of official monitor and that each household rotates into that position on a day when they do not take water following a predetermined schedule (a change from 0 to $\mathrm{R}$ for position rule P1);

2. formalize the rotation system that had evolved only sustained by norms (a change from $\mathrm{S}$ to $\mathrm{R}$ for allocation rule $\mathrm{C} 3$ );

3. create a new rule that both farmers must be present at the time when the water turn changes from one farmer to the other (a change from 0 to $\mathrm{R}$ in aggregation rule $\mathrm{A} 1$ ); and

4. impose a penalty on any farmer who does not follow the first three rules (a change from 0 to $\mathrm{R}$ in payoff rule $\mathrm{Y} 1$ ).

The configuration at $\mathrm{T} 3$ represents this new set of rules (and the two remaining norms) that the Water Users Association could devise in trying to establish some initial rules to keep their water allocation system operating as it had using only norms. If, however, the new farmer was very wealthy and had considerable political power, they might instead fear challenging his demands and give him one day a week to take as much water as he wanted. In T4, they might decide to allocate water on a fixed percentage basis - giving the powerful farmer the percentage of water he demanded, and all of the other 13 farmers an equal percentage of the remaining water. This would represent a change in the allocation rule from $\mathrm{C} 3$ being required (coded as $\mathrm{R}$ ) to $\mathrm{C} 1$ now being permitted (coded as P) and a formula devised to keep the powerful farmer happy while allocating the rest of the water to the other 13 players. All other norms and rulesin-use would stay the same (see the resultant configuration at T4 in Table 2).

Over time, farmers in the Water Users Association might find themselves in a changing economic situation in which more and more settlers move into the region. New settlers are unlikely to know the norms of who can use how much water from which water source. Members of the water association may then find some strangers taking water from their system. That may lead them to decide at T5 to change from a norm, regarding who can use the water, to a rule that requires a farmer to own land within a specified region to take water from this source (B1 would change from S to $\mathrm{R}$ if that rule were adopted as shown in Row $5)$. During this same time period, water becomes scarce, forcing the members of the water association to enact a rule forbidding crops that require large amounts of water ( $\mathrm{S} 3$ would change from 0 to $\mathrm{F}$ when the forbidding rule was adopted). The official monitor position that they had already created could then be charged with evicting anyone not among the authorized landowners if found using water, and enforce the rule forbidding high-water consumption crops.

The above narrative should not be read as a functionalist description of the processes of rule change. Rather, it is an example that we use to highlight 
the mechanics of the analytical tool we have developed in this paper. Clearly, this analytical tool would be equally useful to record instances of systems that attempted but failed to engage in successful collective action or of self-organized systems that were slowly dismantled over time by rule changes of those in power seeking to advantage themselves at the cost of the rest of the group.

\section{Studying change in the context of rule evolution}

Following Campbell's (1965) famous blind-variation-and-selective-retention model, for rule configurations to evolve processes must exist that (1) generate a variety of potential rules, (2) select rules based on information about comparative performance in a particular environment, and (3) retain rules that perform better in regard to criteria such as efficiency, equity, accountability, and sustainability. These three processes are constituents of a general framework of adaptive fit of which the Darwinian notion of organic evolution is but one instance among others. Campbell (1965), Hodgson (2002, 2008), Dennett (1995), Hodgson and Knudsen (2006), among others, have illustrated the myriad of ways in which each of these three processes can play out in social contexts of institutional change. In this paper, we have illustrated how these processes can occur in the context of farmer irrigation systems in Nepal. In the Nepali biophysically heterogeneous and institutional diverse setting, farmers engage in rule selection processes even though it is almost impossible for them to foresee all the outcomes that a change in rules will produce in their irrigation system. Over time - likely through processes of trial and error - they fiddled with rules and norms and eventually learnt that some rule configurations fitted their local needs better than others. They tended to retain those configurations that performed according to their evaluative criteria.

The sketch of the measurement tool presented in the prior section is able to capture the three processes outlined by Campbell (1965) that underlie any form of institutional evolution. Based on the rule typology, a policy analyst can document the institutional configuration of a given action situation at time zero, track what rules and norms are selected (or not) based on a given set of evaluative criteria at time one, and capture which rules and norms are retained at time two and subsequent time periods. Equally important, the approach proposed here allows looking at rules as information-transformation mechanisms in a systematic and rigorous manner (E. Ostrom, 2005: chap. 6).

A number of scholars (Brown and Feldman, 2009; Dopfer et al., 2004; Runciman, 2009) are taking very interesting approaches to the study of the evolution of human societies. In this paper, we focus more on the methods for recording and coding changes in rules used to order human societies so that we have a way of conducting empirical research that records change and can then be used for rigorous testing of various theories about how change occurs. Our analytical tool helps ground different approaches to change and human evolution 
to the nature of rules and rule configurations. Take the micro-meso-macro approach proposed by Dopfer et al. (2004). Dopfer and colleagues argue that in order to understand the highly complex and emergent nature of existence and change in economic evolution, it is necessary to have an analytical framework for evolutionary economics with a micro-meso-macro architecture.

Dopfer et al. (2004) view an economic system as a population of rules, a structure of rules, and a process of rules, where the micro domain refers to the individual carriers of rules and the systems they organize, the macro consists of the population structure of systems of meso, which is where processes of rule change take place. According to Dopfer et al., from an evolutionary perspective, it is not possible to sum micro into macro directly. Therefore, a meso domain linking the micro and macro is a necessary condition. The meso domain affects the macro order and the micro order, and it is composed by three evolutionary phases similar to those proposed by Campbell (1965) mentioned above. In the first phase of origination, agents develop a rule that leads to the design of an organization of people, energy, and materials. At this phase, most rules will fail to be viable, but those that persist are involved in the second phase of diffusion involving adoption and adaptation to a range of organizational contexts. Depending on each case, cooperation or competition will also prompt new rule variants to arise. The result is 'a new micro organization and meso order in the economy, evidenced in transformed market and industrial organizational structures' (Dopfer et al., 2004: 272). In the third phase of retention, replication occurs through the reinforcement and constant tinkering of the meso rules, for example through the embodiment of a rule in law that is enforced.

Dopfer and colleagues' approach, however, does not provide us with enough details about the nature of rules and rule configurations operating at the meso domain to inform how changes might take place and how these changes could be measured. We believe that our discussion on what rule structures look like, what are some of the processes of rule change, and how to measure changes in rule configurations can help to ground the arguments of Dopfer $e t$ al. Note that the meso domain proposed by Dopfer et al. can also be thought of as somewhat equivalent to the collective-choice arena (within the Institutional Analysis and Development [IAD] framework), where the Nepali irrigators came together to discuss and change their irrigation rules based on new water needs or new acquired information of their ever-changing complex-adaptive system.

Clearly, the measuring tool presented in this paper is just the beginning of one way (of many) to study institutional evolution. We chose to illustrate this diagnostic tool through the empirical cases of small irrigation systems in Nepal because their rules-in-use have been well documented in the peer-reviewed literature and - although these small systems are already very complex - it is possible to unpack their complexity and start making sense of it. In the process of knowledge generation about complex adaptive systems, we do not believe it is a good strategy to attempt to tackle very large systems in the first place. With further development, however, there is nothing that we can see to preclude such 
an analytical tool from eventually being useful for studying larger and more complex systems. Most importantly, this research program could take us down the path of dynamic thinking and theory making, away from static theories, empowering us to better understand the complex ever-changing world in which we live.

It is worth restating that it would be naïe to assume that any evolutionary process always leads to better outcomes. In biological systems, competition among populations of diverse species led to the weeding out of many individuals over time who were outcompeted for mates and food in a given environment. Evolutionary processes can also lead to equilibria imposing higher costs on some species and eliminating others. Processes of institutional change can lead to multiple equilibria or none at all! (Foster, 2001). Thus, one should not expect that all locally governed systems will eventually find effective rule configurations. Some will experiment with rule configurations that are far from optimal. And, if the leaders of these systems are somehow advantaged by these rules, they may resist any effort to change. Similarly, as Nelson and Winter (2002) have pointed out, in the context of industrial and technological development, certain rule dynamics can create self-reinforcing mechanisms and path dependencies, making it extremely difficult for actors involved to engage in collective-action processes that can move them away from non-optimal rule configurations and into more desirable rule systems.

\section{When may change lead to improved performance?}

When looked at from a disciplinary perspective, most political scientists have been focused on studying rule systems in the context of legislative behavior. This has limited attention to one out of the many different processes of rule changes worthy of study. If we are to make headway in understanding how rule systems change, and develop a general theory of institutional change, we must widen our view and study a much more diverse set of rule systems. We also need to pay attention to the conditions likely to enhance learning and productive rule evolution.

From considerable research, we can begin to identify the conditions and processes likely to enhance the learning processes of farmers and others making institutional decisions regarding irrigation systems (or other local resources) and the likelihood of an institutional evolutionary process that leads to better, as contrasted to poorer, outcomes. In general, one would expect the rules structuring operational interactions within similar types of situations - such as smaller irrigation systems in a region - to change toward more productive outcomes when:

- most actors affected have some voice in proposing rule changes and making decisions about rule changes;

- most actors within systems have sufficiently large payoffs at stake that they are willing to invest in the transaction costs of searching, debating, and learning about better options; 
- actors with the largest stakes have an interest broadly congruent with increased productivity for the system (this will tend to occur in an irrigation system when the richest farmers are located toward the tail end, are dependent on the others to contribute resources toward the maintenance of the system, or when big differences in the wealth and power of the farmers are not present);

- internal processes within systems have generated substantial variety in the rules used to structure interactions within different systems, leading to a range in performance in regard to agricultural productivity, maintenance of the physical capital, and distribution of income to actors;

- actors are in a social and economic environment where they can learn from successes and failures of others (such as regular meeting places where farmers gossip about the problems they are facing, where officials who are charged with helping farmers learn how to get better productivity from their systems [e.g., extension agents or NGOs], and there are federations of local water associations who meet annually);

- the actors have developed regular procedures for reviewing their experience over time, revising rules and procedures when they evaluate that they could be improved, and recording their changes so that they gain a good history of what they have tried and what results they obtained;

- the systems are in a political environment that encourages local autonomy, but also provides oversight regarding corruption and accountability as well as conflict resolution; and

- biophysical disturbances happen frequently enough so that actors learn how to cope with them rather than occurring only occasionally, leaving farmers unprepared.

The conditions posited above as likely to enhance the quality of institutional evolution have not characterized irrigation investments in most of the developing world during the last several decades (Meinzen-Dick, 2007). The monetary investment in irrigation has been huge, but little attention has been given to the rules used to manage irrigation systems. The World Bank alone contributed around \$10.6 billion in loans for irrigation projects between 1983 and 1999 (Pitman, 2002: 12). International donors were contributing about $\$ 2$ billion per year during the 1990s (Winpenny, 1994). These investments have not generated high returns, while they made a substantial difference in the incentives facing national irrigation officials as well as farmers (Araral, 2005, 2009). Hugh Turral (1995: 1) captured the judgment of many analysts by concluding that irrigation schemes have often underperformed in economic terms, and field research has highlighted substantial shortcomings in management (operation and maintenance), equity, cost-recovery and agricultural productivity'. Some critics, like William Easterly (2001), assert that most of the funding spent by international aid agencies since the 1960s has tragically not achieved promised results (see also Gibson et al., 2005a).

Peter Evans (2004: 31-32) summarizes the dominant method of building institutions to promote development as a form of 'institutional monocropping'. 
Even worse than the initial problems of having the wrong institutions imposed almost everywhere is the 'lock in' that can occur when powerful individuals gain advantage from such institutions, leading to major problems of path dependence (Arthur, 1989; Nelson and Winter, 2002). The powerless and helpless are the ones who pay the big costs. Institutional monocropping generates systems that have little variety in their formal rules in environments with very high levels of diversity in the ecological regions in which they are situated. While expert knowledge can be a great asset in the design and implementation of local resource systems, simply imposing a uniform set of formal rules and ignoring local ecological and social knowledge does not produce the variety needed to learn from experience.

\section{Final reflections}

In our future research, we hope to use the approach outlined to study how rules evolved in multiple cases and then to use agent-based modeling to explore diverse initial conditions and change over time. We know there are both better and worse processes of institutional change and hope to build on and test the proposed approach so as to develop a more solid basis for encouraging processes more likely to lead to improved performance than has been the dominant way of thinking about institutional change and development.

Developing better tools to study the evolution of institutions is one important step we can take to reduce emphasis on institutional monocropping that currently dominates much of social science thinking as well as that of development agencies. We need multiple ways out of this trap. As academics, we can help by being willing to develop more complex theories for explaining the behavior of humans in widely divergent settings (Wilson, 2002; Schmid, 2004). We do not need to be complex, however, just for the sake of being complex, but we do need to get over our simplicity hang-ups. Obviously, our theories will always be simpler than the worlds we study, or we are trying to reproduce these worlds rather than a theory of these worlds. Given the complex, nested systems of the biophysical world, however, we need to develop a social science of complex, nested systems.

\section{References}

Acheson, J. (2003), Capturing the Commons: Devising Institutions to Manage the Maine Lobster Industry, Hanover, NH: University Press of New England.

Acheson, J. and R. Gardner (2004), 'Strategies, conflict, and the emergence of territoriality: the case of the Maine lobster industry', American Anthropologist, 106(2): 296-307.

Agrawal, A. and K. Gupta (2005), 'Decentralization and participation: the governance of common pool resources in Nepal's terai', World Development, 33(7): 1101-1114.

Araral, E. (2005), 'Bureaucratic incentives, foreign aid, and path dependence', Policy Studies, 38(2): 131-157. 
Araral, E. (2009), 'The strategic games that donors and bureaucrats play: an institutional rational choice analysis', Journal of Public Administration Research and Theory, 19(4): 853-871; published online 3 December 2008.

Arthur, W. B. (1989), 'Competing technologies, increasing returns, and lock-in by historical events', Economic Journal, 99: 116-131.

Basurto, X. (2005), 'How locally designed access and use controls can prevent the tragedy of the commons in a Mexican small-scale fishing community', Society and Natural Resources, 18: 643-659.

Basurto, X. (2008), 'Biological and ecological mechanisms supporting marine self-governance: the Seri Callo de Hacha fishery in Mexico', Ecology and Society, 13(2): 20, http://www.ecologyandsociety.org/vol13/iss2/art20/.

Basurto, X. and E. Coleman (2010), 'Institutional and ecological interplay for successful governance of community-based fisheries', Ecological Economics, 69(5): 1094-1103.

Basurto, X., G. Kingsley, K. McQueen, M. Smith, and C. M. Weible (2009), 'A systematic approach to institutional analysis: applying Crawford and Ostrom's grammar', Political Research Quarterly, OnlineFirst, 14 April 2009, doi:10.1177/1065912909334430.

Basurto, X. and E. Ostrom (2009), 'Beyond the tragedy of the commons', Economia delle fonti di energia e dell'ambiente, 52(1): 35-60.

Benjamin, P., W. F. Lam, E. Ostrom, and G. Shivakoti (1994), 'Institutions, incentives, and irrigation in Nepal', Decentralization: Finance and Management Project Report, Associates in Rural Development, Burlington, VT.

Berkes, F. (2007), 'Community-based conservation in a globalized world', Proceedings of the National Academy of Sciences, 104(39): 15188-15194.

Berkes, F. and C. Folke (eds.) (1998), Linking Social and Ecological Systems: Management Practices and Social Mechanisms for Building Resilience, Cambridge: Cambridge University Press.

Bernard, H. R. (2006), Research Methods in Anthropology: Qualitative and Quantitative Approaches, 4th edn, Lanham, MD: Altamira Press.

Blomquist, W. (1992), Dividing the Waters: Governing Groundwater in Southern California, Oakland, CA: ICS Press.

Boyd, R. and P. J. Richerson (1985), Culture and the Evolutionary Process, Chicago: University of Chicago Press.

Brown, M. and W. Feldman (2009), 'Sociocultural epistasis and cultural exaptation in footbinding, marriage form, and religious practices in early 20th-century Taiwan', Proceedings of the National Academy of Sciences, 106(52): 22130-22144.

Campbell, D. T. (1965), 'Variation and selective retention in socio-cultural evolution', in H. R. Barringer, G. I. Blanksten, and R. W. Mack (eds.), Social Change in Developing Areas: A Reinterpretation of Evolutionary Theory, Cambridge, MA: Schenkman, pp. $19-49$.

Campbell, D. T. (1975), 'On the conflicts between biological and social evolution and between psychology and moral tradition', American Psychologist, 30(11): 1103-1126.

Coleman, E. (2009), 'Institutional factors affecting ecological outcomes in forest management', Journal of Policy Analysis and Management, 28(1): 122-146.

Commons, J. R. (1924), Legal Foundations of Capitalism, New York: Macmillan.

Crawford, S. E. S. and E. Ostrom (2005), 'A grammar of institutions', in E. Ostrom, Understanding Institutional Diversity, Princeton, NJ: Princeton University Press, pp. 137-174. Originally published in American Political Science Review, 89(3) (1995): 582-600. 
Dennett, D. C. (1995), Darwin's Dangerous Idea: Evolution and the Meanings of Life, London: Allen Lane.

Dopfer, K., J. Foster, and J. Potts (2004), 'Micro-meso-macro', Journal of Evolutionary Economics, 14: 263-279.

Easterly, W. (2001), The Elusive Quest for Growth: Economists' Adventures and Misadventures in the Tropics, Cambridge: Cambridge University Press.

Evans, P. (2004), 'Development as institutional change: the pitfalls of monocropping and the potentials of deliberation', Studies in Comparative International Development, 39(4): $30-52$.

Foster, J. (2001), 'Competition, competitive selection and economic evolution', in P. Garrouste and S. Ioannides (eds.), Evolution and Path Dependence in Economic Ideas: Past and Present, Cheltenham, UK: Edward Elgar, pp. 107-132.

Gardner, R. and E. Ostrom (1991), 'Rules and games', Public Choice, 70(2): 121-149.

Gautam, U., N. K. Agrawal, and R. Subedi (eds.) (1992), Nepal: Managing Large Surface Irrigation Projects: A Participatory Review, Study Document NEP/89/006, Kathmandu, Nepal: Department of Irrigation and Consolidated Management Services.

Gibson, C., K. Andersson, E. Ostrom, and S. Shivakumar (2005a), The Samaritan's Dilemma: The Political Economy of Development Aid, Oxford, UK: Oxford University Press.

Gibson, C., M. McKean, and E. Ostrom (eds.) (2000), People and Forests: Communities, Institutions, and Governance, Cambridge, MA: MIT Press.

Gibson, C., J. T. Williams, and E. Ostrom (2005b), 'Local enforcement and better forests', World Development, 33(2): 273-284.

Greif, A. and D. D. Laitin (2004), 'A theory of endogenous institutional change', American Political Science Review, 98(4): 633-652.

Hardin, G. (1968), 'The tragedy of the commons', Science, 162: 1243-1248.

Hayes, T. M. and E. Ostrom (2005), 'Conserving the world's forests: are protected areas the only way?', Indiana Law Review, 38(3): 595-617.

Henry, A. D. (2009), 'The challenge of learning for sustainability: a prolegomenon to theory', Research in Human Ecology, 16(2): 131-141.

Hilpinen, R. (ed.) (1981), New Studies in Deontic Logic: Norms, Actions, and the Foundations of Ethics, Dordrecht, Holland: D. Reidel.

Hilton, R. (1990), Cost Recovery and Local Resource Mobilization: An Examination of Incentives in Irrigation Systems in Nepal, Decentralization: Finance and Management Project Report, Burlington, VT: Associates in Rural Development.

Hodgson, G. M. (2002), 'Darwinism in economics: from analogy to ontology', Journal of Evolutionary Economics, 12: 259-281.

Hodgson, G. M. (2004), The Evolution of Institutional Economics: Agency, Structure, and Darwinism in American Institutionalism, London: Routledge.

Hodgson, G. M. (2008), 'How Veblen generalized Darwinism', Journal of Economic Issues, 42(2): 399-405.

Hodgson, G. M. (2009), 'The ontology of institutional evolution', prepared for the workshop on 'Do Institutions Evolve?', Schumann Center in the European University Institute, Florence, Italy, 8-9 May 2009.

Hodgson, G. M. and T. Knudsen (2006), 'Why we need a generalized Darwinism, and why a generalized Darwinism is not enough', Journal of Economic Behavior and Organization, 61(1): 1-19.

Holling, C. S. (1973), 'Resilience and stability of ecological systems', Annual Review of Ecology and Systematics, 4: 1-23. 
Janssen, M. (2007), 'Coordination in irrigation systems: an analysis of the Lansing-Kremer model of Bali', Agricultural Systems, 93: 170-190.

Janssen, M., R. Goldstone, F. Menczer, and E. Ostrom (2008), 'Effect of rule choice in dynamic interactive spatial commons', International Journal of the Commons, 2(2): 288-312.

Janssen, M., R. Holahan, A. Lee, and E. Ostrom (2010), 'Lab experiments for the study of social-ecological systems', Science 328(5978): 613-617.

Janssen, M. and E. Ostrom (2006a), 'Governing social-ecological systems', in K. L. Judd and L. Tesfatsion (eds.), Handbook of Computational Economics II: Agent-Based Computational Economics, Amsterdam: Elsevier, pp. 1465-1509.

Janssen, M. and E. Ostrom (2006b), 'Adoption of a new regulation for the governance of common-pool resources by a heterogeneous population', in J.-M. Baland, P. Bardhan, and S. Bowles (eds.), Inequality, Cooperation, and Environmental Sustainability, Princeton, NJ: Princeton University Press, pp. 60-96.

Joshi, N. N., E. Ostrom, G. Shivakoti, and W. F. Lam (2000), 'Institutional opportunities and constraints in the performance of farmer-managed irrigation systems in Nepal', Asia-Pacific Journal of Rural Development, 10(2): 67-92.

King, G., R. O. Keohane, and S. Verba (1994), Designing Social Inquiry: Scientific Inference in Qualitative Research, Princeton, NJ: Princeton University Press.

Kofinas, G. P. (2005), 'Caribou hunters and researchers at the co-management interface: emergent dilemmas and the dynamics of legitimacy in power sharing', Anthropologica, 47: 179-196.

Lam, W. F. (1998), Governing Irrigation Systems in Nepal: Institutions, Infrastructure, and Collective Action, Oakland, CA: ICS Press.

Lam, W. F., M. Lee, and E. Ostrom (1994), 'An institutional analysis approach: findings from the NIIS on irrigation performance', in J. Sowerwine, G. Shivakoti, U. Pradhan, A. Shukla, and E. Ostrom (eds.), From Farmers' Fields to Data Fields and Back: A Synthesis of Participatory Information Systems for Irrigation and Other Resources, Colombo, Sri Lanka: International Irrigation Management Institute, and Rampur, Nepal: IAAS, pp. 69-93.

Lam, W. F. and E. Ostrom (2010), 'Analyzing the dynamic complexity of development interventions: lessons from an irrigation experiment in Nepal', Policy Sciences, 43(1): 1-25; published online 5 May 2009.

Lansing, J. S. (1991), Priests and Programmers: Technologies of Power in the Engineered Landscape of Bali, Princeton, NJ: Princeton University Press.

Lansing, J. S. (2006), Perfect Order: Recognizing Complexity in Bali, Princeton, NJ: Princeton University Press.

Lansing, J. S. and J. Kremer (1993), 'Emergent properties of landscape', American Anthropologist, 95(1): 97-115.

Levin, S. A. (1998), 'Ecosystems and the biosphere as complex adaptive systems', Ecosystems, 1: 431-436.

Lustick, I. S. (2009), 'Evolution and historical institutionalism: tropes without theory', prepared for the workshop on 'Do Institutions Evolve?', Schumann Center in the European University Institute, Florence, Italy, 8-9 May 2009.

Meinzen-Dick, R. (2007), 'Beyond panaceas in water institutions', Proceedings of the National Academy of Sciences, 104(39): 15200-15206.

Nelson, R. R. (2009), 'How do institutions evolve?', prepared for the workshop on 'Do Institutions Evolve?', Schumann Center in the European University Institute, Florence, Italy, 8-9 May 2009. 
Nelson, R. R. and S. G. Winter (1982), An Evolutionary Theory of Economic Change, Cambridge, MA: Harvard University Press.

Nelson, R. R. and S. G. Winter (2002), 'Evolutionary theorizing in economics', Journal of Economic Perspectives, 16(2): 23-46.

Netting, R. McC. (1974), 'The system nobody knows: village irrigation in the Swiss Alps', in T. E. Downing and M. Gibson (eds.), Irrigation's Impact on Society, Tucson: University of Arizona Press, pp. 67-75.

Netting, R. McC. (1981), Balancing on an Alp: Ecological Change and Continuity in a Swiss Mountain Community, New York: Cambridge University Press.

North, D. C. (2005), Understanding the Process of Institutional Change, Princeton, NJ: Princeton University Press.

Orebech, P., F. Bosselman, J. Bjarup, D. Callies, M. Chanock, and H. Petersen (2005), The Role of Customary Law in Sustainable Development, Cambridge: Cambridge University Press.

Ostrom, E. (1990), Governing the Commons: The Evolution of Institutions for Collective Action, New York: Cambridge University Press.

Ostrom, E. (1995), 'Self-organization and social capital', Industrial and Corporate Change, 4(1): 131-159.

Ostrom, E. (1999), 'Coping with tragedies of the commons', Annual Review of Political Science, 2: 493-535.

Ostrom, E. (2005), Understanding Institutional Diversity, Princeton, NJ: Princeton University Press.

Ostrom, E. (2007a), 'A diagnostic approach for going beyond panaceas', Proceedings of the National Academy of Sciences, 104(39): 15181-15187.

Ostrom, E. (2007b), 'Institutional rational choice: an assessment of the institutional analysis and development framework', in P. A. Sabatier (ed.), Theories of the Policy Process, 2nd edn, Boulder, CO: Westview Press, pp. 21-64.

Ostrom, E., R. Gardner, and J. Walker (1994), Rules, Games, and Common-Pool Resources, Ann Arbor: University of Michigan Press.

Ostrom, E. and H. Nagendra (2006), 'Insights on linking forests, trees, and people from the air, on the ground, and in the laboratory', Proceedings of the National Academy of Sciences, 103(51): 19224-19231.

Ostrom, E., J. Walker, and R. Gardner (1992), 'Covenants with and without a sword: selfgovernance is possible', American Political Science Review, 86(2): 404-417.

Ostrom, V. (1980), 'Artisanship and artifact', Public Administration Review, 40(4): 309-317.

Ostrom, V. (1991), The Meaning of American Federalism: Constituting a Self-Governing Society, Oakland, CA: ICS Press.

Ostrom, V. (1997), The Meaning of Democracy and the Vulnerability of Democracies: A Response to Tocqueville's Challenge, Ann Arbor: University of Michigan Press.

Ostrom, V. (2008a), The Intellectual Crisis in American Public Administration, 3rd edn, Tuscaloosa: University of Alabama Press.

Ostrom, V. (2008b), The Political Theory of a Compound Republic: Designing the American Experiment, 3rd edn, Lanham, MD: Lexington Books.

Pitman, G. (2002), Bridging Troubled Waters: Assessing the WB Water Resources Strategy, Washington, DC: WP-Operations Evaluation Department.

Poteete, A., M. Janssen, and E. Ostrom (2010), Working Together: Collective Action, the Commons, and Multiple Methods in Practice, Princeton, NJ: Princeton University Press.

Ragin, C. C. (2000), Fuzzy-Set Social Science, Chicago, IL: University of Chicago Press. 
Regmi, A. (2007), 'Water security and farmer managed irrigation systems of Nepal', in F. Rotberg and A. Swain (eds.), Natural Resources Security in South Asia: Nepal's Water, Stockholm, Sweden: Institute for Security and Development Policy, pp. 67-109.

Richerson, P. J. and R. Boyd (2005), Not by Genes Alone: How Culture Transformed Human Evolution, Chicago, IL: University of Chicago Press.

Runciman, W. G. (2009), The Theory of Cultural and Social Selection, Cambridge: Cambridge University Press.

Schlager, E. and E. Ostrom (1992), 'Property-rights regimes and natural resources: a conceptual analysis', Land Economics, 68(3): 249-262.

Schmid, A. A. (2004), Conflict and Cooperation: Institutional and Behavioral Economics, Malden, MA: Blackwell.

Shivakoti, G. (1992), 'Farmers' perceptions of system effectiveness, level of participation and equity in farmer and agency managed irrigation systems in Nepal', presented at the third annual conference of the International Association for the Study of Common Property, Washington, DC, September, pp. 17-20.

Shivakoti, G. and E. Ostrom (2001), Improving Irrigation Governance and Management in Nepal, Oakland, CA: ICS Press.

Shivakoti, G., G. Varughese, E. Ostrom, A. Shukla, and G. Thapa (eds.) (1997), 'People and participation in sustainable development: understanding the dynamics of natural resource systems', Bloomington: Indiana University, Workshop in Political Theory and Policy Analysis; Rampur, Chitwan, Nepal: Tribhuvan University, Institute of Agriculture and Animal Science.

Shivakoti, G., D. Vermillion, W. F. Lam, E. Ostrom, U. Pradhan, and R. Yoder (eds.) (2005), Asian Irrigation in Transition: Responding to Challenges, New Delhi, India: Sage.

Spiertz, H. L. J. (1991), 'The transformation of traditional law: a tale of people's participation in irrigation management on Bali', Landscape and Urban Planning, 20: 189196.

Stake, J. (2005), 'Evolution of rules in a common law system: differential litigation of the fee tail and other perpetuities', Florida State University Law Review, 32(2): 401-424.

Tang, S. Y. (1992), Institutions and Collective Action: Self-Governance in Irrigation, San Francisco, CA: ICS Press.

Turral, H. (1995), 'Recent trends in irrigation management: changing directions for the public sector', no. 5, September, Overseas Development Institute, London.

Veblen, T. (1898), 'The instinct of workmanship and the irksomeness of labor', American Journal of Sociology (September): 187-201. Reprinted in Veblen (1934).

von Wright, G. H. (1951), 'Deontic logic', Mind, 60: 1-15.

von Wright, G. H. (1963), Norm and Action: A Logical Enquiry, London: Routledge \& Kegan Paul.

Wasserman, S. and K. Faust (1994), Social Network Analysis: Methods and Applications, Cambridge: Cambridge University Press.

Weissing, F. and E. Ostrom (1991), 'Irrigation institutions and the games irrigators play: rule enforcement without guards', in R. Selten (ed.), Game Equilibrium Models II: Methods, Morals, and Markets, Berlin: Springer-Verlag, pp. 188-262.

Weissing, F. and E. Ostrom (1993), 'Irrigation institutions and the games irrigators play: rule enforcement on government- and farmer-managed systems', in F. W. Scharpf (ed.), Games in Hierarchies and Networks: Analytical and Empirical Approaches to the Study of Governance Institutions, Frankfurt: Campus Verlag; Boulder, CO: Westview Press, pp. 387-428. 
Wilson, J. (2002), 'Scientific uncertainty, complex systems, and the design of common-pool institutions', in E. Ostrom, T. Dietz, N. Dolšak, P. C. Stern, S. Stonich, and E. Weber (eds.), The Drama of the Commons, National Research Council, Committee on the Human Dimensions of Global Change, Washington, DC: National Academies Press, pp. 327-359.

Wilson, J., L. Yan, and C. Wilson (2007), 'The precursors of governance in the Maine lobster fishery', Proceedings of the National Academy of Sciences, 104(39): 15212-15217.

Winpenny, J. T. (1994), Managing Water as an Economic Resource, New York: Routledge. 